\title{
Juventudes e vulnerabilidades: dilemas e propostas
}

\author{
Ilana Paiva \\ Marlos Bezerra \\ Universidade Federal do Rio Grande do Norte
}

O dossiê elaborado para esta edição da revista Estudos de Psicologia é o resultado de uma conjugação de esforços implicados em uma articulação ao mesmo tempo local e nacional. Assim surgiu o Simpósio "Juventudes da América Latina: Novas propostas para velhos dilemas", realizado nos dias 30 e 01 de outubro de 2011, na UFRN e, a partir dele, o esforço de publicação de uma parte das importantes discussões realizadas.

Ainda assim, a publicação do dossiê não traduz a dimensão do evento. O público, estimado em 350 pessoas, ultrapassou a meta fixada para o Simpósio. Com relação aos trabalhos apresentados, o Simpósio contou com seis eixos temáticos (Metodologias de pesquisa e intervenção com adolescentes e jovens; Práticas profissionais na interface com a adolescência e juventude; Políticas públicas; Trabalho e Inventividades; Violências, cenários sociais e direitos humanos; Vulnerabilidades e Produção de saúde; e Culturas periféricas e movimentos de resistência coletiva). Na sessão de Pôsteres, foram apresentados 45 trabalhos, e na sessão de comunicação oral 47 refletindo o esforço de estudantes engajados em pesquisas de graduação e pós-graduação de diversas localidades brasileiras. Quanto aos convidados, o Simpósio contou com a participação de 24 pesquisadores, sendo 12 de outras IFES do Brasil (UFRGS, UFPB, UFC, UFF, UEMG, UnB e UCB), uma pesquisadora da Universidad Javeriana da Colômbia, outra do PPGCS da UFRN, um Juiz de Direito (RN) área da Infância e Juventude e um representante da ANCED (Associação Nacional dos Centros de Defesa da Criança e do Adolescente), além de três pesquisadores de outros cursos de Psicologia de Natal (UNI-RN e UnP).

Cumpre-nos contextualizar, igualmente, as parcerias que viabilizaram a realização do evento.

Do ponto de vista local, o Observatório da População infanto-juvenil em contexto de violência - OBIJUV, criado há dois anos e coordenado por nós com a participação de outros docentes do PPGPsi. Apesar do pouco tempo de existência, o OBIJUV mobilizou um contingente importante de engajados alunos de graduação e do Programa de Pós-graduação. O OBIJUV é um grupo interbases que congrega docentes de vários grupos de pesquisa do Departamento de Psicologia que colaboram em suas atividades como: Grupo de Pesquisa Marxismo e Educação - GPM\&E, Núcleo de Estudos da Criança e adolescência - NESCIA, Laboratório de Estudos em Tanatologia e Práticas de Humanização em Saúde - LETHS, Grupo de Estudos Subjetividade e Desenvolvimento Humano - GESDH. Com tamanha diversidade, o elemento agregador é, certamente, a necessidade de denúncia e a postura propositiva em torno dos contextos de vulnerabilização de crianças, adolescentes e jovens na região metropolitana da cidade do Natal (RN).

Nacionalmente, o Simpósio, assim como esta publicação, é fruto da parceria com o Grupo de Trabalho (GT) da Associação Nacional de Pesquisa e Pós-graduação em Psicologia (ANPEPP), denominado Juventude, Resiliência e Vulnerabilidade, coordenado pela professora Silvia Helena Koller (Universidade Federal do Rio Grande do Sul). O GT é integrado por pesquisadores de todas as regiões do Brasil, bem como por membros da Colômbia, Portugal e Estados Unidos, e o seu objetivo principal é manter a discussão teórica, metodológica e ética acerca das pesquisas conjuntas em andamento sobre temáticas como juventude, resiliência, psicologia positiva, fatores de proteção e risco, redes de apoio social, exposição à violência, etc.

A diversidade teórica e metodológica presente nos artigos demonstra a diversidade que existe no interior do GT.

Como será claramente verificado na leitura dos artigos, os pesquisadores convidados realizam em seus textos tanto uma análise crítica em diversos cenários do país, como ainda, esforçam-se por alinhar algumas proposições para as questões discutidas. Esse é também o espírito que anima nossas ações. Ao trabalharmos nessa edição, reafirmamos o nosso compromisso com o campo de estudos da infância e juventude em contextos de violência material, social e simbólica, ao passo em que nos inscrevemos, também, em uma postura propositiva junto aos diversos atores sociais que tomam parte na execução das políticas públicas voltadas para este importante segmento da população brasileira. Acreditamos que o rigor da pesquisa acadêmica pode aliar-se a uma postura ético-política, no qual o pesquisador também contribui de modo mais próximo dos grupos e instituições com os quais atua, com a problematização dos caminhos e descaminhos da sociedade em que vive.

Finalizamos agradecendo o esforço reiterado de nossas editoras Katie Almondes e Fívia Lopes, no suporte em todos os trâmites para a materialização da proposta.

Ilana Paiva e Marlos Bezerra Editores convidados 